accurately described the phenomena under discussion.

Rose noted that the question of the research objective was important. There was a tendency to examine the question of discrimination (prejudice) by focussing on ethnic groups whereas the agency itself should be the object. Brosnan followed this up by pointing out that there was a need to go to different parts of the agency because prejudice can occur at different levels, from managers, from other workers, and from customers.

\title{
GROUP 4. MIGRANT LABOUR AND POLICY
}

Members : Grant Andrews, Arthur Grimes, John Martin, David Pearson.

\section{Major questions}

Two broad areas of research were pinpointed. The first was an examination of migrant workers, that is transient workers who are not integrated into the social context of the area in which they are living; the seasonal flows of labour for horticulture for example.

The second area of research is related more directly to permanent internal and external migration. Research areas raised include :

(1) Examining the categories of people migrating (both emigration and immigration). Categories include nationality, occupation, age, sex, race, wealth and whether the migration is permanent or temporary.

(2) Factors behind the migration, e.g. job prospects, wages (both gross and net), political climate and social reasons such as family or refugee status.

(3) An examination of the job related categories and market factors affecting people who decline to migrate as well as those who do migrate.

(4) What has been the social impact on communities of migration (both internal and external)?

(5) The way migration has affected individuals - has it been better or worse than expected? Has their position improved?

(6) The construction of a regional matrix of internal migration, especially for young people would be useful. Is there a relationship between migration flows in such a matrix and changes in industry; do different age groups respond differently to industry shutdowns, etc.?

(7) How do we define migrant labour? Do we need to make distinctions between internal and external migration? Are there different characteristics between those 2 flows?

(8) What are the differences in the characteristics of ethnic migrant labour? What is the precise nature of the difference between migrants from say the Pacific Islands and the United Kingdom? Is there a difference between Maori migrants to the cities and Pacific Island migrants? 
42.

(9) When does migrant 1abour stop becoming migrant labour? Do we just look at the first or also at the subsequent generations of migrants?

(10) What is the relationship between migration and policy. For example to what extent is policy systematically related to economic cycles, etc.?

Existing answers The questions regarding transient labour are not answered well at present. While there is some reasonable data on broad groups of migrants, wealth data is lacking, as is research on the reasons for migration. Also there has been little follow up work on migrants.

Questions of highest priority The transient worker area requires a labour force survey examining past, present and future labour market activity. The characteristics of and factors behind migration need to have a priority on policy making. For social purposes, examination of ethnic considerations is important particularly in identifying the differential effects of ethnicity (i.e. after standardising for skills, etc.) on various aspects of labour market activity.

Major obstacles to this research The major obstacle to work on transient labour is the "slipperiness of the customer". The inability of the Department of Statistics to undertake a labour force survey has been a major drawback to research in this area. In border migration, there may be problems arising from the short-term/ permanent and 1ong-term breakdown, especially when short-term migrants stay longer than 12 months, or vice versa.

There is a lack of data on desired, as opposed to actual, migration flows, but to a large extent this is unavoidable. For historical study, there is a difficulty in deciding how policy was formulated. Obtaining documentation on policy is a large exercise and documents may not, in any case, reveal the actual reasons behind the final migration policy decisions.

Other relevant observations Work on transient workers relates to the need for facilities for such workers (e.g. motor camps, etc.). There is a need for ongoing work into project workers (e.g. on the Southern hydro schemes, Northland and Taranaki major projects). Can those projects be co-ordinated to ensure ongoing work? A1so, can seasonal work for transients be co-ordinated? Questions of unionisation of casual workers are also important.

Attitudes to migrants are relevant. The relationship of those attitudes to policy and particularly to discriminatory policies is of interest.

An examination of the different attitudes of different countries, e.g. the United Kingdom, New Zealand, Australia and Canada to migrants, reflecting different national identities is also of interest.

\section{DISCUSSION}

Poot noted that the consequences of migration are less well studied compared 
to causes. To do this work, one needs to know the internal workings of a regional economy.

Imray stated that there was a trade-off between migration and training policy. In the 1960 s, economies fe1t they could simply import 1abour. This has now changed with attention turning more directly to (re)training. Andrews observed that imported labour tends to change jobs more often which raises the question as to how well such migrants fulfil the gaps in labour demand. We therefore need to know more about occupational history of migrants. Rose suggested that the present scope for international migration may be being reduced and Brosnan noted that New Zealand's low unemployment leve1s may have been due to our fine tuning of the labour market by the use of international migration.

\section{GROUP 5. MEASURING HIDDEN UNEMPLOYMENT}

Members : Robert Bowie, Rosemary Graham, Nancy McBeth, Kim Saffron.

Genera1 observations

(1) Hidden unemployment represents a wastage of persons both economically and socially. It seems to be a significant phenomenon but the actual data resources with respect to New Zealand are limited and/or indirect.

(2) Hidden unemployment has to be defined. We understand it to represent those people who are not in the labour force but would be if they thought they could obtain employment. They are not unemployed and seeking work but may have been before they dropped out of the labour force. They have reached the stage where, having become "discouraged" they are no longer seeking work. Thus hidden unemployment may be defined to include the underemployed who register as well as the discouraged unemployed who do not.

(3) The best data sources currently available are : (a) the Social Indicators Survey 1980-81, Department of Statistics, and (b) the work on women's unemployment in Palmerston North by Susan Shipley. The proposed household labour force survey could provide further information if and when implemented.

(4) Further information on hidden unemployment would be best obtained by a labour force survey. Regionally based surveys are quite useful but the actual magnitude of the problem would be best determined by a national labour force survey with suitable sample size. In such surveys, other characteristics, e.g. age, sex, social/ethnic group, of the hidden unemployed could be gauged. Problems arise in financing of such a household survey, but other labour market information could also be obtained in such a survey. Repeating the survey at intervals would be most useful 